\title{
Second sacral sacralalar-iliac (S2AI) screw placement in adult degenerative scoliosis (ADS) patients: an imaging study
}

Bing $\mathrm{Wu}^{\dagger}$, Kai Song ${ }^{*}$, Junyao Cheng, Pengfei Chi, Zhaohan Wang ${ }^{\dagger}$ and Zheng Wang*

\begin{abstract}
Background: The imaging characteristics of sacral sacralalar-iliac (S2Al) screw trajectory in adult degenerative scoliosis (ADS) patients will be determined.

Methods: S2Al screw trajectories were mapped on three-dimensional computed tomography (3DCT) reconstructions of 40 ADS patients. The starting point, placement plane, screw template, and a circle centered at the lowest point of the ilium inner cortex were set on these images. A tangent line from the starting point to the outer diameter of the circle was selected as the axis of the screw trajectory. The related parameters in different populations were analyzed and compared.

Results: The trajectory length of S2AI screws in ADS patients was $12.00 \pm 0.99 \mathrm{~cm}$, the lateral angle was $41.24 \pm 3.92^{\circ}$, the caudal angle was $27.73 \pm 6.45^{\circ}$, the distance from the axis of the screw trajectory to the iliosciatic notch was $1.05 \pm 0.81 \mathrm{~cm}$, the distance from the axis of the screw trajectory to the upper edge of the acetabulum was $1.85 \pm 0.33 \mathrm{~cm}$, and the iliac width was $2.12 \pm 1.65 \mathrm{~cm}$. Compared with females, the lateral angle of male ADS patients was decreased, but the trajectory length was increased $(P<0.05)$. Compared to patients without ADS in previous studies, the lateral angle of male patients was larger, the lateral angle of female patients was increased, and the caudal angle was decreased $(P<0.05)$.
\end{abstract}

Conclusions: There is an ideal trajectory of S2AI screws in ADS patients. A different direction should be noticed in the placement of S2AI screws, especially in female patients.

Keywords: S2Al screw, Adult degenerative scoliosis, Spinal fusion, Pelvis, Screw trajectory

\section{Background}

With aging of the population, the overall incidence of adult degenerative scoliosis (ADS) is $8.3-68 \%[1,2]$. ADS is a three-dimensional deformity of the spine that is often accompanied by morphologic changes (pelvic retroversion and coronal tilt) [3, 4]. Long segmental fixation is often required when coronal and sagittal imbalances are caused by severe deformities. Surgical treatment is

*Correspondence: wangzheng20200328@163.com

${ }^{\dagger}$ Bing Wu, Kai Song, and Zhaohan Wang the first author

Department of Orthopedics, the Fourth Medical Centre, Chinese PLA

General Hospital, 51 Fucheng Road, Haidian District, 100048 Beijing, China thought to be the only way to relieve symptoms in ADS patients who fail to respond to conservative treatment.

Surgeons face severe challenges for long-segment fixed fusion to S1 in ADS patients. Specifically, the S1 vertebral body has a structural disadvantage that is characterized by short and thick pedicles and a stress concentration is noted in the lumbosacral region after long segment fixation. In addition, ADS patients often have co-existing osteoporosis, which leads to a decrease in bone-screw interface control, resulting in poor lumbosacral fusion, false joint formation, and even orthopedic failure [5-7]. Moreover, the incidence of complications is higher when 
long-segment fixation is fused to S1. Kim [8] reported that the rate of screw loosening in adult spinal deformities is $24.4 \%$ after distal fusion to S1 alone. Emami [9] showed that the non-fusion rate of lumbosacral is approximately $20 \%$ when long-segment fusion reaches the sacrum alone. Kim [10] found that the fusion rate of lumbosacral pseudoarthroplasty with long-segment fixation is $17 \%$. Therefore, it is necessary to extend the fixation to the pelvis to increase the mechanical strength of the lumbosacral region.

Compared with the traditional spinal and pelvic fixation technology, the sacral sacralalar-iliac (S2AI) screw fixation technology has the advantages of less tissue dissection, less trauma, small incision, high fixation strength, and good compliance with a lumbosacral pedicle screw [11-15]. In recent years, the trajectory of the S2AI screw and evaluation of its clinical effect have become major research interests. Previous studies on S2AI screw trajectories at home and abroad are all derived from 3DCT measurements or cadaver studies in healthy people and patients with lumbar degenerative disc disease [11, 12, 16-18].

The pelvic morphology of the ADS population might be different from the healthy population or patients with lumbar spine disease. Therefore, the data obtained from the latter two populations would be appropriate for the target population that needs S2AI screw insertion. In addition, a study of the S2AI screw trajectory based on the sample of ADS patients has not been reported. In this study the trajectory of S2AI screws was standardized by 3DCT reconstruction images of the lumbosacral pelvic region in ADS patients, the related parameters were measured and analyzed to provide the imaging anatomic basis of S2AI screw fixation, and the characteristics of S2AI screw trajectory in ADS patients were summarized.

\section{Methods}

\section{Inclusion and exclusion criteria}

The study had been approved by the Ethics Committee of our hospital and was conducted under the requirements for good clinical practice. A total of 40 patients with degenerative scoliosis who were admitted to our department between September 2015 and December 2016 were selected for imaging measurements. The inclusion criteria included the following: (1) patients $\geq 50$ years of age diagnosed with lumbar degenerative scoliosis and a Cobb angle of at least $10^{\circ}$. (2) The design of the S2AI screw track trajectory was standardized through three-dimensional reconstruction of $\mathrm{CT}$ images of the lumbosacral pelvis region, and the relevant parameters were measured and analyzed. The exclusion criteria included the following: 1 . Recurrent scoliosis or deformity before skeletal maturity, such as idiopathic, neuromuscular, and congenital scoliosis. 2. Scoliosis caused by spinal trauma, spinal surgery, tumors, or infections. (3) Scoliosis resulting from unequal lengths of the lower limbs or non-primary diseases of the hip, knee, or ankle. (4) Less than 50 years of age. Our study population consisted of 40 patients (15 males and 25 females) with a mean age (and standard deviation) of $65 \pm 6.73$ years (range, 51-81 years).

Due to CT examination radiation exposure, a control group in the general population without ADS was not established in this study. Therefore, the relevant literature of S2AI screws in domestic and foreign databases was retrieved as the control group. The literature inclusion criteria were as follows: complete main parameters of screw trajectory, such as screw trajectory length, caudal angle, and lateral angle, were measured and all data are expressed as $-\mathrm{x} \pm \mathrm{s}$. A total of 4 studies were retrieved [19-22].

\section{Standardized design of S2AI screw trajectory}

Three-dimensional scanning of the thoracolumbar, lumbar, and sacral segments of the spine was performed with a sliding mode 40 slice spiral CT scanning (Somatom Sensation 40; Siemens, Erlangen, Germany) in our hospital, and the scanning range also included the proximal femur of the bilateral hip joints. After being transmitted to the post-processing workstation of the Syngo software system, image reconstruction and reorganization were carried out with a reconstruction gap of $1.5 \mathrm{~mm}$.

The base of the lateral sacral crest on the midline between the lower edge of the S1 dorsal foramina and the upper edge of the S2 dorsal foramina was designated as the starting point, and was also the entry point of the nail (Fig. 1). The placement plane of the S2AI screw trajectory

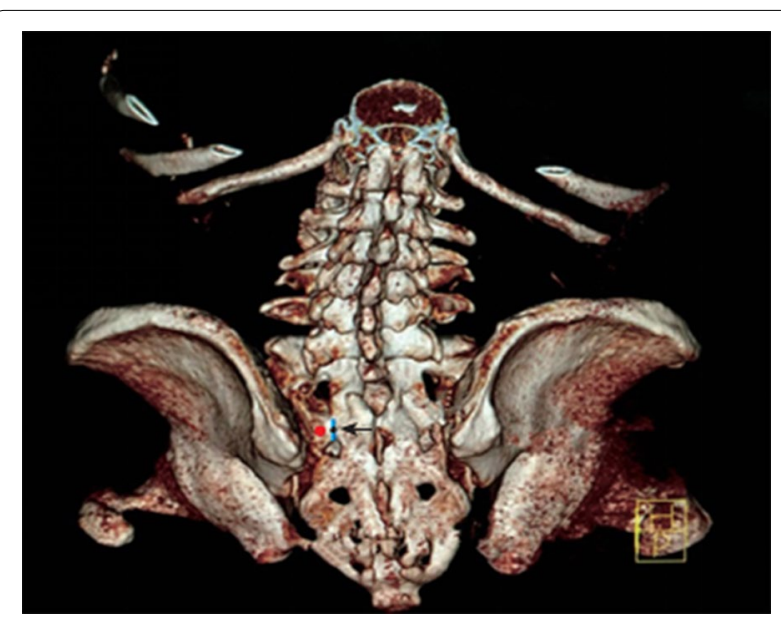

Fig. 1 Three-dimensional CT reconstruction of the lumbosacral pelvis: red dot represents the insertion point/ starting point 
was determined from the starting point to the lower margin of the anterior inferior iliac spine. A 10-mm diameter screw was the design template and a distance of $0.5 \mathrm{~cm}$ from the anterior cortical bone in the iliac bone was designated as the axis of the safe track of the nail path, which was also the best nail path (Fig. 2a, b).

\section{Measurement of parameters}

(1) The transverse plane measurement (Fig. 2c) was as follows: (1)The lateral angle was the angle between the projection of the screw trajectory on the cross- section and the median line. (2) The trajectory length was the distance between the starting point and the lateral cortex along the trajectory. (3) The iliac width was the narrowest distance between the inner and outer cortex of the ilium along the screw trajectory.

(2) The sagittal plane measurement (Fig. 2d) was as follows: (1) The caudal angle was the angle between the projection of the screw trajectory on the sagittal plane and the horizontal line. (2) The distance from the axis of the screw trajectory to the iliosciatic notch was the shortest vertical distance from the
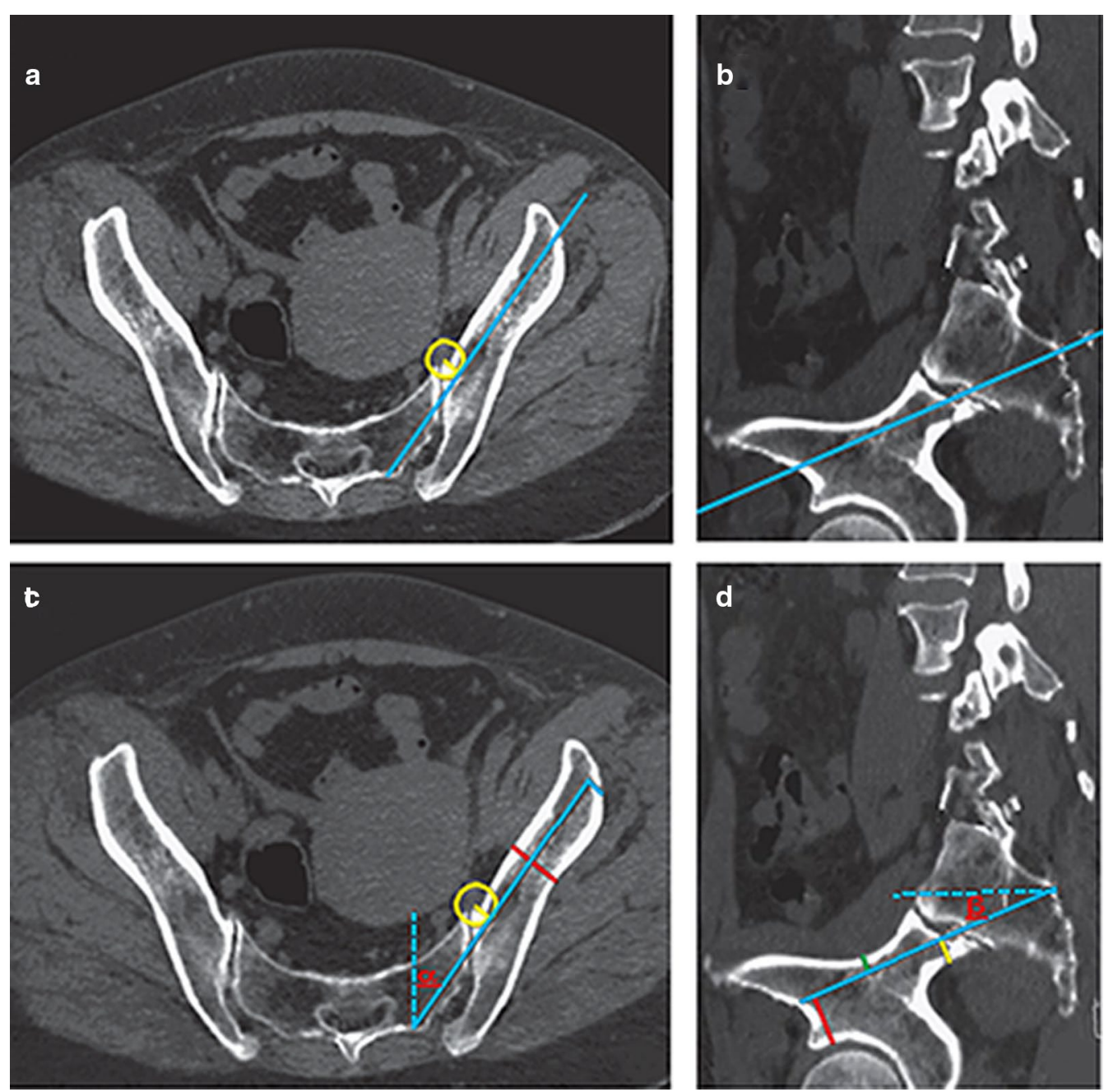

Fig. 2 Standardizeddesign of S2Al screw trajectory and measurement of relevant parameters. a Transverse image of screw placement plane. The blue line representsthe axis of the nail track, and the yellow line represents the distance betweenthe anterior cortex of the ilium and the axis of the screw trajectory by $5 \mathrm{~mm} . \mathbf{b}$ Sagittal image of screw placement plane. The blue line indicates the point ofinsertion to the inferior margin of anterior inferior iliac spine. c Transverseimage of screw placement plane. Alpha is the lateral angle of the screwtrajectory, the blue line represents the length of the screw trajectory, andthe red line represents the width of the ilium. $\mathbf{d}$ Sagittal image of screw placement plane. Beta is the caudal angleof the screw trajectory, the yellow line represents the distance from the screwtrajectory to the ischial notch, the green line represents the distance fromthe screw trajectory to the upper iliac cortex, and the red line represents thedistance from the screw trajectory to the acetabulum 
highest point of the ischial large notch to the screw trajectory, which represents the space distance of the screw trajectory below the sagittal plane. (3) The distance from the axis of the screw trajectory to the upper edge of the acetabulum was the shortest vertical distance between the lowest point of the bone above the screw trajectory and represented the space distance of the screw trajectory above the sagittal plane. (4) The distance between the screw trajectory and the acetabulum was the shortest vertical distance between the highest point of the acetabulum and the screw trajectory. The lumbar lordosis, pelvic incidence, pelvic tilt, and sacral slope also were measured.

\section{Statistical analysis}

Statistical analysis was carried out using SPSS 22.0 (SPSS, Inc., Chicago, IL, USA). The measurement parameters are expressed as $-\mathrm{x} \pm \mathrm{s}$. The differences in parameters between the males and females in our study were analyzed using an independent samples $t$-test. The main parameters of the S2AI screw trajectory were compared with the results reported in the literature using the SNK - $Q$ test. A statistically significant difference was considered at a $p<0.05$.

\section{Results}

Trajectory parameters of the S2AI screw in ADS patients

The trajectory length of the S2AI screw in all ADS patients was $12.00 \pm 0.99 \mathrm{~cm}$, the lateral angle was $41.24^{\circ} \pm 3.92^{\circ}$, the caudal angle was $27.73^{\circ} \pm 6.45^{\circ}$, the distance from the axis of the screw trajectory to the iliosciatic notch was $1.05 \pm 0.81 \mathrm{~cm}$, the distance from the axis of the screw trajectory to the upper edge of the acetabulum was $1.85 \pm 0.33 \mathrm{~cm}$, and the iliac width was $2.12 \pm 1.65 \mathrm{~cm}$.

\section{Comparison of main parameters in ADS patients of different genders}

Because there was no significant difference between the left and right S2AI screw trajectory parameters in patients of the same gender, the main parameter data of the screw trajectory in two sides were combined and analyzed according to different genders. The male lateral angle $\left(39.47^{\circ} \pm 1.76^{\circ}\right)$ decreased by nearly $3^{\circ}$ compared with the female lateral angle $\left(42.30^{\circ} \pm 4.48^{\circ} ; P<0.05\right)$. The length of the male screw trajectory was $12.40 \pm 0.83 \mathrm{~cm}$, while length of the female screw trajectory was $11.75 \pm 1.01 \mathrm{~cm}$, which increased by $0.55 \mathrm{~cm}$ on average in males compared to females $(P<0.05)$. The differences in caudal angle, lumbar lordosis, pelvic incidence, pelvic tilt and sacral slope between the genders were not statistically significant (Table 1).

\section{Comparison of the main parameters of S2AI screw} trajectories in ADS patients based on the extant literature The parameters of S2AI screw trajectories reported in the extant literature were collected and compared (Tables 2, $3,4,5,6$, and 7 ). The length of S2AI screw trajectories in ADS patients was longer, but there was no significant difference compared with previous publications (Tables 2 and 3).

In the current study the lateral angle of the male ADS patients was $39.47^{\circ} \pm 1.76^{\circ}$, which was greater than the healthy population previously reported $(P<0.05)$. The

Table 1 Parameters of S2AI screw in patients with ADS $(x \pm s)$

\begin{tabular}{|c|c|c|c|c|c|}
\hline & Total(40) & Male(15) & Female(25) & tvalue & $P$ value \\
\hline Lateral angle $\left(^{\circ}\right)$ & $41.24 \pm 3.92$ & $39.47 \pm 1.76$ & $42.30 \pm 4.48$ & 2.33 & 0.025 \\
\hline Caudal angle $\left(^{\circ}\right)$ & $27.73 \pm 6.45$ & $28.00 \pm 6.39$ & $27.56 \pm 6.61$ & -0.21 & 0.838 \\
\hline Length of trajectory(cm) & $12.00 \pm 0.99$ & $12.40 \pm 0.83$ & $11.75 \pm 1.01$ & -2.07 & 0.045 \\
\hline
\end{tabular}

Table 2 The length of the trajectory in male patients with ADS compared with that reported in the previous literature

\begin{tabular}{|c|c|c|c|c|c|c|}
\hline & Sample size & Total $(\mathrm{cm})$ & Left(cm) & Right(cm) & $t$ value $^{a}$ & $P$ value \\
\hline Current study & 15 & $12.40 \pm 0.83$ & $12.38 \pm 0.86$ & $12.42 \pm 0.84$ & - & - \\
\hline Yamada etc. [19] & 40 & - & $12.15 \pm 10.30$ & $12.18 \pm 10.10$ & left: - 0.09; right: - 0.09 & left: 0.932;right: 0.928 \\
\hline Zhu etc. [20] & 30 & - & $12.13 \pm 8.33$ & $12.06 \pm 7.54$ & left: $-0.12 ;$ right: -0.18 & left: 0.909;right: 0.856 \\
\hline Yuan etc. [21] & 25 & $12.09 \pm 7.89$ & - & - & -0.15 & 0.881 \\
\hline Wang etc. [22] & 30 & $12.00 \pm 6.52$ & - & - & -0.24 & 0.815 \\
\hline
\end{tabular}

\footnotetext{
a The statistical values are the data in each literature compared with the corresponding data in this study, the same below
} 
Table 3 The length of the trajectory in female patients with ADS compared with that reported in the previous literature

\begin{tabular}{lllllll}
\hline & Sample size & Total $(\mathrm{cm})$ & Left $(\mathrm{cm})$ & Right$(\mathrm{cm})$ & tvalue $^{\text {a }}$ & $P$ value $^{\text {a }}$ \\
\hline Current study & 25 & $11.75 \pm 1.01$ & $11.75 \pm 1.02$ & $11.76 \pm 1.08$ & - & - \\
Yamada etc. [19] & 40 & - & $11.38 \pm 9.60$ & $11.27 \pm 9.10$ & left: -0.19 ; right: -0.27 & left: 0.849;right: 0.790 \\
Zhu etc. [20] & 30 & - & $11.48 \pm 9.44$ & $11.57 \pm 8.24$ & left: -0.14 ;right: -0.11 & left: 0.888;right: 0.909 \\
Yuan etc. [21] & 25 & $11.52 \pm 8.80$ & - & - & -0.13 & 0.897 \\
Wang etc. [22] & 30 & $10.95 \pm 4.63$ & - & - & -0.85 & 0.399
\end{tabular}

a The statistical values are the data in each literature compared with the corresponding data in this study, the same below

Table 4 The caudal angle in male patients with ADS compared with that reported in the previous literature

\begin{tabular}{|c|c|c|c|c|c|c|}
\hline & Sample size & Total $\left({ }^{\circ}\right)$ & Left $\left({ }^{\circ}\right)$ & $\operatorname{Right}\left({ }^{\circ}\right)$ & tvalue ${ }^{a}$ & $P$ value ${ }^{a}$ \\
\hline Current study & 15 & $28.00 \pm 6.39$ & $27.73 \pm 6.68$ & $28.27 \pm 6.10$ & - & - \\
\hline Yamada etc. [19] & 40 & - & $27.65 \pm 6.80$ & $28.00 \pm 7.20$ & left: -0.11 ;right: 0.13 & left: 0.911;right: 0.898 \\
\hline Zhu etc. [20] & 30 & - & $29.15 \pm 8.60$ & $29.96 \pm 8.28$ & left: -0.56 ;right: -0.70 & left: 0.579;right: 0.489 \\
\hline Yuan etc. [21] & 25 & $29.56 \pm 8.38$ & - & - & 0.62 & 0.539 \\
\hline Wang etc. [22] & 30 & $31.02 \pm 7.43$ & - & - & 1.39 & 0.170 \\
\hline
\end{tabular}

a The statistical values are the data in each literature compared with the corresponding data in this study, the same below

Table 5 The lateral angle in male patients with ADS compared with that reported in the previous literature

\begin{tabular}{|c|c|c|c|c|c|c|}
\hline & Sample size & Total $\left({ }^{\circ}\right)$ & Left $\left({ }^{\circ}\right)$ & $\operatorname{Right}\left({ }^{\circ}\right)$ & $t$ value $^{\mathrm{a}}$ & $P$ value $^{\mathrm{a}}$ \\
\hline Current study & 15 & $39.47 \pm 1.76$ & $39.60 \pm 1.99$ & $39.33 \pm 2.02$ & - & - \\
\hline Yamada etc. [19] & 40 & - & $37.90 \pm 7.00$ & $37.70 \pm 7.50$ & left: -0.092 ;right: -0.83 & left: 0.361;right: 0.412 \\
\hline Zhu etc. [20] & 30 & - & $36.49 \pm 3.14$ & $37.16 \pm 3.14$ & left: - 3.49;right: - 2.43 & left: 0.001;right: 0.019 \\
\hline Yuan etc. [21] & 25 & $36.11 \pm 3.38$ & - & - & -3.56 & 0.001 \\
\hline Wang etc. [22] & 30 & $40.25 \pm 2.84$ & - & - & 0.99 & 0.326 \\
\hline
\end{tabular}

a The statistical values are the data in each literature compared with the corresponding data in this study, the same below

Table 6 The caudal angle in female patients with ADS compared with that reported in the previous literature

\begin{tabular}{|c|c|c|c|c|c|c|}
\hline & Sample size & Total $\left({ }^{\circ}\right)$ & Left $\left({ }^{\circ}\right)$ & $\operatorname{Right}\left(^{\circ}\right)$ & $t$ value ${ }^{a}$ & $P$ value \\
\hline Current study & 25 & $27.56 \pm 6.61$ & $27.68 \pm 6.30$ & $27.44 \pm 7.71$ & - & - \\
\hline Yamada etc. [19] & 40 & - & $33.40 \pm 6.40$ & $33.90 \pm 6.60$ & left: 3.53;right: 3.60 & $<0.001$ \\
\hline Zhu etc. [20] & 30 & - & $34.50 \pm 6.56$ & $35.72 \pm 7.53$ & left: 3.91 ;right: 4.02 & $<0.001$ \\
\hline Yuan etc. [21] & 25 & $35.11 \pm 7.03$ & - & - & 3.91 & $<0.001$ \\
\hline Wang etc. [22] & 30 & $34.16 \pm 6.02$ & - & - & 4.14 & $<0.001$ \\
\hline
\end{tabular}

${ }^{a}$ The statistical values are the data in each literature compared with the corresponding data in this study, the same below

Table 7 The lateral angle in female patients with ADS compared with that reported in the previous literature

\begin{tabular}{lllllll}
\hline & Sample size & Total $\left({ }^{\circ}\right)$ & Left $\left({ }^{\circ}\right)$ & ${\text { Right }\left({ }^{\circ}\right)}$ & t value & $P$ value \\
\hline Current study & 25 & $42.30 \pm 4.48$ & $41.92 \pm 5.10$ & $42.68 \pm 3.98$ & - & - \\
Yamada etc. [19] & 40 & - & $32.80 \pm 7.60$ & $32.40 \pm 7.10$ & left: -5.29 ;right: -6.61 & $<0.001$ \\
Zhu etc. [20] & 30 & - & $35.72 \pm 3.79$ & $36.27 \pm 3.27$ & left: -5.17 ; right: -6.56 & $<0.001$ \\
Yuan etc. [21] & 25 & $36.69 \pm 3.21$ & - & - & 5.09 & $<0.001$ \\
Wang etc. [22] & 30 & $39.25 \pm 2.64$ & - & - & 3.46 & $<0.001$ \\
\hline
\end{tabular}

\footnotetext{
a The statistical values are the data in each literature compared with the corresponding data in this study, the same below
} 
caudal angle was $28.00^{\circ} \pm 6.39^{\circ}$ and there was no significant difference between the male ADS patients and the healthy population (Tables 4 and 5).

The caudal angle of the female ADS patients was $27.56^{\circ} \pm 6.61^{\circ}$, which was significantly less than healthy people previously reported $(P<0.05)$. The lateral angle was $42.30^{\circ} \pm 4.48^{\circ}$, which was significantly greater than healthy people $(P<0.05$; Tables 6 and 7$)$.

\section{Discussion}

The screw entry points of S2AI based on a review of the literature are not fixed positions, but relatively similar to each other [16, 19-28]. The medial base of the lateral sacral ridge on the horizontal line between the lower and upper edges of the posterior sacral foramen of S2 is considered as the entry point, which is similar to the entry point selected by Yamada et al. [19] and William and Jeffery [29]. Indeed, the medial base of the lateral sacral ridge is the key to determining the trajectory plane of the S2AI screw, and at the same time, the length and width of the internal part of the ilium must be considered. Thus, the line from the most convex point of the posterior superior iliac spine to the anterior inferior iliac spine is the longest diameter line in the ilium [30], and the medullary cavity is wider toward the caudal end of the ilium [31]. In the current study the location of the entry point was close to the posterior superior iliac spine, and the length of the screw trajectory and the safety of screw placement were considered. Therefore, the direction of the screw should be toward the inferior margin of the anterior inferior iliac spine, which simplifies the steps to identify the screw placement plane, which was confirmed by constantly rotating the image in previous studies [2022]. Of note, the measurement method had little effect on the differences in each study. In the current study, a $10-\mathrm{mm}$ diameter screw was used as the design template. The more forward the S2AI screw trajectory in the crosssection, the longer the screw trajectory. Based on this feature, the $5-\mathrm{mm}$ distance from the anterior cortex bone in the ilium, which is applicable to the diameter screws in clinical practice, was taken as the safety trajectory in the current study. Our results showed that the selected iliac plane was relatively wide and thick. The distance between the sagittal screw trajectory and the ischial notch, the distance between the screw trajectory and the iliac cortex, and the distance between the screw trajectory and the acetabulum were all $>5 \mathrm{~mm}$, thus the location of the S2AI screw was in the bone structure of both the crosssection and sagittal plane, which is safe and reliable.

The results of the current study showed that there was no significant difference in the length of the screw trajectory between the male and female patients with ADS compared with previous studies, which means the data of S2AI screws in our study and previous studies are suitable for ADS patients. In addition to the length of the screw trajectory, the direction of S2AI screw placement in females with ADS was quite different from the previous studies. The results of this study showed that the caudal angle of female ADS patients was significantly less $\left(6-8^{\circ}\right)$ than that reported in the literature, while the lateral angle was significantly greater $\left(3-6^{\circ}\right)$ than that reported in the literature $(\mathrm{P}<0.05)$. The larger lateral angle was mainly due to the difference in pelvis morphology between ADS patients and the general population. The difference in pelvis morphology is not only the cause of ADS, but also the result of ADS. The larger lateral angle of ADS in women suggests that the extroversion should increase as much as possible when inserting S2AI screws. According to previous data, the angle of screw placement is often small, which results in the penetration of the medial cortex of the pelvis and the injury of pelvic organs and blood vessels. In addition, the change in screw trajectory will be increasingly difficult. Because the majority of ADS patients are women, attention should focus on the increased lateral angle. In contrast, the caudal angle of ADS in female patients was smaller than the healthy population, and was related to the overall sagittal imbalance and the lumbar lordosis angle reduction in women with ADS. The loss of lumbar lordosis in ADS patients indicates that the pelvis is tilted backward, which is equal to the reduction of caudal angle in the horizontal position. In spite of the differences in lumbar lordosis of the prone and standing positions, there is still a close relationship between the two positions [32, 33].Therefore, the caudal angle reported in the extant literature is actually based on the general population with normal spine pelvis sagittal parameters. This finding suggests that when S2AI screws are inserted in clinical practice, the caudal angle should be relatively reduced to avoid injuring other tissues by cutting out the large ischial incision.

In the current study the lateral angle of male ADS patients was larger than the healthy population reported in some studies $(\mathrm{P}<0.05)$, but there was no significant difference in the caudal angle. Based on our analysis we believe that the severe sagittal imbalance of the spine pelvis in male patients was less than female patients, and the same was true in male patients with ADS included in this study; however, it was difficult to reach a conclusion similar to that in female ADS patients due to the small sample size. In this paper there were some shortcomings. Because the subjects in this study were ADS patients with detailed CT information of the pelvis, it was impossible to obtain a larger sample size. In addition, although the relevant research suggests that the prone and supine positions are closely related in pelvis rotation, there is still a lack of CT data in 
the supine position to simulate the state of the prone position intraoperatively, as mainly reflected by the caudal angle.

\section{Conclusions}

In conclusion, there is an ideal trajectory of S2AI screws in ADS patients. There was no statistical significance in the difference of the S2AI screw length between ADS patients and the non-ADS population. A different direction should be noted in the placement of S2AI screws, especially in female ADS patients in whom the lateral angle should increase and the caudal angle should decrease.

\section{Abbreviations \\ S2Al: second sacral sacralalar-iliac; ADS: adult degenerative scoliosis; 3DCT: three-dimensional computed tomography.}

\section{Acknowledgements}

None.

\section{Authors' contributions}

BW, KS, and ZW are guarantors of integrity of the entire study. BW contributed to study concepts, study design, definition of intellectual content, literature research, clinical studies, experimental studies, data acquisition, data analysis, manuscript preparation, manuscript editing, and manuscript review. ZHW took part in study concepts, definition of intellectual content, literature research, clinical studies, experimental studies, data acquisition, data analysis, and statistical analysis. JYC conducted clinical and experimental studies, and performed data acquisition, data analysis, and statistical analysis. PFC contributed to experimental studies, data acquisition, data analysis, and statistical analysis. KS contributed to study design. ZW was in charge of study design and manuscript review. All authors read and approved the manuscript.

\section{Funding}

This research received no specific grant from any funding agency in the public, commercial, or not-for-profit sectors.

\section{Availability of data and materials}

The datasets used and/or analyzed during the current study are available from the corresponding author upon reasonable request.

\section{Declarations}

Ethics approval and consent to participate

All procedures conducted in studies involving human participants were in accordance with the ethical standards of the institutional and/or national research committee and with the 1964 Helsinki Declaration and its later amendments or comparable ethical standards. This study was approved by the Ethics Committee of the Chinese PLA General Hospital. Written informed consent was obtained.

\section{Consent for publication}

Informed verbal consent was obtained from all individual participants included in the study.

\section{Competing interests}

The authors declare that they have no competing interests.

Received: 9 October 2020 Accepted: 9 March 2021

Published online: 06 April 2021

\section{References}

1. Schwab F, Dubey A, Gamez L, El Fegoun AB, Hwang K, Pagala M, Farcy JP. Adult scoliosis: prevalence, SF-36, and nutritional parameters in an elderly volunteer population. Spine (Phila Pa 1976). 2005;30:1082-5.

2. Silva FE, Lenke LG. Adult degenerative scoliosis: evaluation and management. Neurosurg Focus. 2010;28:E1.

3. Jean L. Influence of age and sagittal balance of the spine on the value of the pelvic incidence. Eur Spine J. 2014;23:1394-9.

4. Lee JH, Na KH, Kim JH, Jeong HY, Chang DG. Is pelvic incidence a constant, as everyone knows? Changes of pelvic incidence in surgically corrected adult sagittal deformity. Eur Spine J. 2016;25:3707-14.

5. Kuklo TR. Principles for selecting fusion levels in adult spinal deformity with particular attention to lumbar curves and double major curves. Spine (Phila Pa 1976). 2006;31:132 -8.

6. Shen FH, Mason JR, Shimer AL, Arlet VM. Pelvic fixation for adult scoliosis. Eur Spine J. 2013;22:265-75

7. Moshirfar A, Rand FF, Sponseller PD, Parazin SJ, Khanna AJ, Kebaish KM, Stinson JT, Riley LH. Pelvic fixation in spine surgery. Historical overview, indications, biomechanical relevance, and current techniques. J Bone Joint Surg Am. 2005;87:89-106.

8. Kim JB, Park SW, Lee YS, Nam TK, Park YS, Kim YB. The effects of spinopelvic parameters and paraspinal muscle degeneration on $\mathrm{s} 1$ screw loosening. J Korean Neurosurg Soc. 2015;58:357-62.

9. Emami A, Deviren V, Berven S, Smith JA, Hu SS, Bradford DS. Outcome and complications of long fusions to the sacrum in adult spine deformity: luque -galveston, combined iliac and sacral screws, and sacral fixation. Spine (Phila Pa 1976). 2002;27:776-86.

10. Kim YJ, Bridwell KH, Lenke LG, Cho KJ, Edwards CC, Anthony S. Rinella. Pseudarthrosis in adult spinal deformity following multi-segmental instrumentation and arthrodesis. J Bone Joint Surg Am. 2006;88:721-8.

11. Cunningham BW, Sponseller PD, Murgatroyd AA, Kikkawa J, Tortolani PJ. A comprehensive biomechanical analysis of sacral alar iliac fixation: an in vitro human cadaveric model. J Neurosurg Spine. 2019;30:367-75.

12. Sponseller PD, Zimmerman RM, Ko PS, Pull Ter Gunne AF, Mohamed AS, Chang TL, Kebaish KM. Low profile pelvic fixation with the sacral alar iliac technique in the pediatric population improves results at two-year minimum follow-up. Spine (Phila Pa 1976). 2010;35:1887-92.

13. Banno T, Ohishi T, Hasegawa T, Yamato Y, Kobayashi S, Togawa D, Yasuda T, Matsuyama Y. Accuracy of iliac screws insertion in adult spinal deformity surgery: relationship between misplacement and the iliac morphologies. Clin Spine Surg. 2017;30:E407-11.

14. Kuklo TR, Bridwell KH, Lewis SJ, Baldus C, Blanke K, Iffrig TM, Lenke LG. Minimum 2-year analysis of sacropelvic fixation and L5-S1 fusion using S1 and iliac screws. Spine (Phila Pa 1976). 2001;26:1976-83.

15. Harimaya K, Mishiro T, Lenke LG, Bridwell KH, Koester LA, Sides BA. Etiology and revision surgical strategies in failed lumbosacral fixation of adult spinal deformity constructs. Spine (Phila Pa 1976). 2011;36:1701-10.

16. Chang TL, Sponseller PD, Kebaish KM, Fishman EK. Low profile pelvic fixation: anatomic parameters for sacral alar-iliac fixation versus traditional iliac fixation. Spine (Phila Pa 1976). 2009;34:436-40.

17. Elder BD, Ishida W, Lo SL, Goodwin CR, Kosztowski TA, Bydon A, Gokaslan ZL, Wolinsky JP, Sciubba DM, Witham TF. Use of S2-alar-iliac screws associated with less complications than iliac screws in adult lumbosa-cropelvic fixation. Spine (Phila Pa 1976). 2017;42:E142-9.

18. Hoernschemeyer DG, Pashuck TD, Pfeiffer FM. Analysis of the S2 alar - iliac screw as compared with the traditional iliac screw: does it increase stability with sacroiliac fixation of the spine? Spine J. 2017;17:875-9.

19. Yamada K, Higashi T, Kaneko K, Ide M, Sekiya T, Saito T. Optimal trajectory and insertion accuracy of sacral alar iliac screws. Acta Orthop Traumatol Turc. 2017:51:313-8.

20. Zhu F, Bao HD, Yuan S, Wang B, Qiao J, Zhu ZZ, Liu Z, Ding YT, Qiu Y. Posterior second sacral alar iliac screw insertion: anatomic study in a Chinese population. Eur Spine J. 2013;22:1683-9.

21. Yuan S, Qiu Y, Zhu F, et al. Computed tomography study of posterior S2 alar-iliac screw placement in adults. Chin J Spine Spinal Cord. 2011;21:987-91.

22. Wang Y, Zhang XS, Luo CC, Yang QZ, Yang XQ, Wang Y. Assessing difference between S1 and S2 alar-iliac screw placement by computed tomography in Chinese adults population. Acad J Chin PLA Med Sch. 2016;37:591-4. 
23. O'Brien JR, Yu WD, Bhatnagar R, Sponseller P, Kebaish KM. An anatomic study of the S2 iliac technique for lumbopelvic screw placement. Spine (Phila Pa 1976). 2009;34:E439-42.

24. Liu Z, Qiu Y, Yan H, Hu ZS, Zhu F, Qiao J, Xu LL, Wang B, Yu Y, Qian BP, Zhu ZZ. S2 alar-iliac fixation: a powerful procedure for the treatment of kyphoscoliosis. Orthop Surg. 2016;8:81-4.

25. Yilmaz E, Abdul-Jabbar A, TawfikT, Iwanaga J, Schmidt CK, Chapman J, Blecher R, Tubbs RS, Oskouian RJ. S2 alar-iliac screw insertion: technical note with pictorial guide. World Neurosurg. 2018:113:e296-301.

26. Park JH, Hyun SJ, Kim KJ, Jahng TA. Free hand insertion technique of S2 sacral alar-iliac screws for spino-pelvic fixation: Technical note, acadaveric study. J Korean Neurosurg Soc. 2015;58:578-81.

27. Choi HY, Hyun SJ, Kim KJ, Jahng TA, Kim HJ. Freehand S2 alar-iliac screw placement using kwire and cannulated screw: technical case series. J Korean Neurosurg Soc. 2018;61:75-80.

28. Park YS, Hyun SJ, Park JH, Kim KJ, Jahng TA, Kim HJ. Radiographic and clinical results of freehand S2 alar-iliac screw placement for spinopelvic fixation: an analysis of 45 consecutive screws. Clin Spine Surg. 2017;30(7):E877-82
29. Wiilliam CWJ, Jeffery RS. Campbell's Operative Orthopaedics Vols 4. 13th eds. Wang Z, Lu N, Zhu ZZ. et al: Peking University Medical Press. 2018;pp. 2002-5.

30. Schildhauer TA, McCulloch P, Chapman JR, Mann FA. Anatomic and radiographic considerations for placement of transiliac screws in lumbopelvic fixations. J Spinal Disord Tech. 2002;15:199-205.

31. Sang XG, Zhang LP, Liu HC. Clinical anatomy of lumboiliac fixation. Chin J Clin Anat. 2007;25:156-9.

32. Harimaya K, Lenke LG, Mishiro T, Bridwell KH, Koester LA, Sides BA Increasing lumbar lordosis of adult spinal deformity patients via intraoperative prone positioning. Spine (Phila Pa 1976). 2009;34:2406-12.

33. Li JJ, Guo HF, Zhang YG, Zhang YG, Song K, Tang XY, Su XJ. Changes of sagittal spino-pelvic alignment in scoliosis patients in standing and supine position. Acad J Chin PLA Med Sch. 2015;36:603-6.

\section{Publisher's note}

Springer Nature remains neutral with regard to jurisdictional claims in published maps and institutional affiliations.
Ready to submit your research? Choose BMC and benefit from:

- fast, convenient online submission

- thorough peer review by experienced researchers in your field

- rapid publication on acceptance

- support for research data, including large and complex data types

- gold Open Access which fosters wider collaboration and increased citations

- maximum visibility for your research: over $100 \mathrm{M}$ website views per year

At BMC, research is always in progress.

Learn more biomedcentral.com/submissions 